\title{
Optimization of a New GaN-Based Blue Laser Diode with a Quadruple Asymmetric Waveguide for High Efficiency Performance
}

\author{
Zahra Danesh Kaftroudi \\ Department of Engineering Sciences, Faculty of Technology and Engineering, East of Guilan, \\ University of Guilan, Rudsar-Vajargah, Iran
}

Corresponding author email: zahraadanesh@guilan.ac.ir

Regular paper: Received: May. 31, 2020, Revised: Jun. 23, 2021, Accepted: Jul. 24, 2021, Available Online: Jul. 26, 2021, DOI: 10.52547/ijop.15.1.101

\begin{abstract}
In this work, for the first time, the improved lasing performance of a blue GaNbased laser diode is demonstrated by the introduction and vertical optimization of a new quadruple asymmetric waveguide structure. In the new proposed waveguide structure, in the first step, p-waveguide and electron blocking layers have been omitted. Then a triple asymmetry was considered for the design of an AlGaNp-cladding layer inside the waveguide structure. The performances of the conventional and proposed laser structures were theoretically studied using the photonic integrated circuit simulator in 3D simulation software. The 3deminsional simulations of carrier transport, optical wave- guiding and self-heating were combined self-consistently in the software. A good agreement was achieved between simulations and experiments by careful choice of different material parameters in the physical models. The effects of the AlGaN p-cladding layer properties on the performance of the new quadruple asymmetric waveguide GaN-based laser were theoretically studied. Threshold current, output power, and operation voltage were compared for different composition of $\mathrm{Al}$, doping, and thickness of the AlGaN p-cladding layer. According to the simulation results, the optimized values of Al composition, doping, and thickness of the AlGaN p-cladding layer obtained for high-power performance.
\end{abstract}

KEYWORDS: GaN-based laser diode, Optimization, Simulation, AlGaN- cladding, PICS3D, Quadruple asymmetric waveguide.

\section{I.INTRODUCTION}

Over the last few years, semiconductor laser diodes have found their way into our daily life. Laser diodes (LDs) are excellent light sources for many optical applications since they have unique characterizations. The $\mathrm{m} 400 \mathrm{~nm}$ blueviolet GaN LDs are useful for various usages such as atomic spectroscopy, communications and super-capacity optical storage systems. Despite the excellent demonstrations of UV nitride-lasers based on $\mathrm{GaN}$, there are still many challenges on the optimization of their performances [1].

At present, powerful LDs employ large optical waveguides with a few micron thicknesses. The waveguide includes an active region containing several quantum wells (or quantum dot active layers) that are often at the centre of it [2], [3]. However, at a very high injection current, the power roll-over has been observed in the broadened waveguide. Several suggestions have been offered for waveguide engineering to increase the laser diode output power [4]. Eventually, the employment of an asymmetric waveguide layer would be a way to balance the carrier confinement and high output power in LD design [5]-[8]. Single-mode waveguide structures using asymmetric waveguide structures are of great interest because of their unique features. The main idea of these structures is to alter the optical field into ndoped layers, which have lower free carrier absorption compared to p-doped layers. The 
asymmetric waveguide structure allows a small overlap between the optical field and p-doped layers, enabling the control of optical losses in the laser cavity, which is a serious problem at low current. Therefore, an asymmetric waveguide design is suggested to answer highpower laser requirements such as low optical loss as well as low thermal and electrical resistance.

The optical confinement factor, $\Gamma_{\mathrm{MQW}}$, introduces overlapping between the active layer and fundamental optical mode. The greater $\Gamma_{\mathrm{MQW}}$ causes to increase the modal gain and thus it must be as high as possible to decrease the threshold current and increase the slope efficiency [9]. In the laser diode with the asymmetric waveguide design, $\Gamma_{\mathrm{MQw}}$ is typically low owing to the substantial shift of the optical intensity peak into the n-side of LD waveguide that causes to enhance the threshold current and decrease the slope efficiency.

In conventional blue LDs, significant leakage of electrons always exists due to the weak confinement of electrons in shallow quantum wells. Theoretical and experimental works have provided numerous methods to decrease the electron leakage current and enhance nitride laser diode efficiency. Traditional specifications among best nitride LDs, which have been proved, include a p-type AlGaN layer with a high-bandgap barrier, which grows immediately above the active region. This layer stops the electron leakage. In recent years, many different structural approaches have been suggested to improve the GaN-based laser diode performance with p-type AlGaN EBL [10]-[14]. Nitride laser with an asymmetric waveguide structure causes to remove the $\mathrm{p}$ type AlGaN EBL; thus, the p-cladding layer must be used for the confinement of injected electrons. Therefore, this layer has a vital role in the optimum operation of nitride LDs.

To create high-efficiency LDs, well-set theoretical modelling is a required strategy to optimize available LD structures and understand the internal behaviour of LDs with physical respect. Today, simulation is highly used in the industry. Photonic integrated circuit simulator in 3D (PICS3D) is a 3D computeraided design simulator for LDs.

This paper, two laser structures are studied to enhance laser power with a reasonable threshold current; slope efficiency and operating voltage. The conventional symmetric InGaN quantum well laser with the $\mathrm{AlGaN}$ electron blocking layer (EBL) is simulated. Nakamura presents the LD structure and experimental analyses [15]. A good agreement is obtained between simulations and experiments by proper selection of different material parameters in physical models. In the new structure a quadruple asymmetric in the waveguide design is proposed. As it is known, in a conventional symmetric structure, the nside and $\mathrm{p}$ - side of the LD are quite similar i. e. the waveguide and the cladding layers consist of layers with the same semiconductor composition, equal thickness, $\mathrm{n}$ and $\mathrm{p}$ doping. In the new proposed structure, there is no such symmetric configuration in the waveguide design. At the first step, p-doping $\mathrm{GaN}$ waveguide layer and AlGaN EBL are omitted. So the waveguide layer exits on the $n$ - side and this layer is deleted from the $\mathrm{p}$ - side of the new structure. This is the first stage of the quadruple asymmetric steps. At the next steps a triple asymmetric design is considered on the p$\mathrm{AlGaN}$ cladding layer properties in the waveguide of the new LD structure. This means that the composition, thickness and doping of the p- cladding layer are changed, so its three characterizations are different from $n$ - cladding layer. Thus, the $\mathrm{p}$ - side of the waveguide has four differences compared with the n- side of it. Hence it is called quadruple asymmetric waveguide. Threshold current, output power, slope efficiency and operating voltage are compared for different composition of $\mathrm{Al}$, thickness, and doping of the AlGaN p-cladding layer. The simulation results reveal a new optimized quadruple asymmetric waveguide structure.

The physical models are introduced in section I. The laser structures and material parameters used in this work are presented in section II. The discussion of theoretical findings and interpretations are given in section III. 


\section{Physical Models}

The governing equations which describe the behaviour of the laser performance are well explained in the simulator manual [16]. The PICS3D simulation program self-consistently finds solutions of famous electrical equations such as Poisson, current continuity, carrier transport, quantum mechanical gain, and heat transfer equations. The carrier transport is described based on the classic drift-diffusion model, with the thermionic-emission model used at the heterojunctions. Lateral optical modes are calculated by the effective-index method. In the strained QWs the conduction bands are assumed to be parabolic, and the valence bands are calculated by the $6 \times 6 \mathrm{k} . \mathrm{p}$ method for the valance-band mixing.

For successful simulation, several material parameters for different semiconductor layers used in the laser structure such as refractive index $\left(\mathrm{n}_{\mathrm{r}}\right)$, thermal conductivity $\left(\mathrm{k}_{\mathrm{L}}\right)$ and mobility $(\mu)$ must be properly chosen. There are different methods for calculating each of these parameters, in this section the physical methods used to calculate them are summarized. For the LD optical cavity designing, refractive index changing with material composition is mostly more significant than its absolute value. Compared to experimental results on $\mathrm{Al}_{\mathrm{x}} \mathrm{Ga}_{1-\mathrm{x}} \mathrm{N}$ with Al mole fraction less than $38 \%$, the Adachi model is proved to be the most exact model using experimental fitting parameters. The $\mathrm{In}_{\mathrm{x}} \mathrm{Ga}_{1-\mathrm{x}} \mathrm{N}$ refractive index is selected by linear interpolation [17]. Electron and hole mobility are the main material parameters in the electrical and thermal simulations of the LD. An empirical phrase, which is widely used to model the carrier mobility, is the CaugheyThomas estimation. The thermal conductivities are approximately evaluated after taking into account the alloy composition and interface scattering impact in phonons on thermal conductivity.

\section{III.DEVICE STRUCTURES AND Material PARAMETERS}

In this simulation, the InGaN laser structure consists of a $3 \mu \mathrm{m}$ thick n-type $\mathrm{GaN}$ layer. For this layer, the refractive index is $n_{r}=2.54$, the thermal conductivity is $\mathrm{k}_{\mathrm{L}}=1.3 \mathrm{Wcm}^{-1} \mathrm{~K}^{-1}$ and the mobility is $\mu=410 \mathrm{~cm}^{-2} \mathrm{~V}^{-1} \mathrm{~S}^{-1}$. Besides, an ntype $\mathrm{In}_{0.05} \mathrm{Ga}_{0.95}$ layer with the thickness of $0.1 \mu \mathrm{m}$, the refractive index $\mathrm{n}_{\mathrm{r}}=2.55$, the thermal conductivity $\mathrm{k}_{\mathrm{L}}=0.7 \mathrm{Wcm}^{-1} \mathrm{~K}^{-1}$ and the mobility $\mu=390 \mathrm{~cm}^{-2} \mathrm{~V}^{-1} \mathrm{~S}^{-1}$ is located above the substrate. Moreover a $0.5 \mu \mathrm{m}$ thick n-type $\mathrm{Al}_{0.08} \mathrm{Ga}_{0 .}{ }_{92} \mathrm{~N}$ layer with the refractive index $\mathrm{n}_{\mathrm{r}}=2.48$, the thermal conductivity $\mathrm{k}_{\mathrm{L}}=0.2 \mathrm{Wcm}^{-1} \mathrm{~K}^{-1}$ and the mobility $\mu=10 \mathrm{~cm}^{-2} \mathrm{~V}^{-1} \mathrm{~S}^{-1}$ is considered. A $0.1 \mu \mathrm{m}$ thick n-type $\mathrm{GaN}$ layer completes nside of laser diode. In this layer the refractive index, the thermal conductivity and the mobility are $2.54,1.3 \mathrm{Wcm}^{-1} \mathrm{~K}^{-1}$ and $410 \mathrm{~cm}^{-2} \mathrm{~V}^{-}$ ${ }^{1} \mathrm{~S}^{-1}$, respectively. At heterojunctions in the semiconductor devices, thermionic emission must be considered in the drift and diffusion model. Furthermore conduction band $\left(\Delta \mathrm{E}_{\mathrm{c}}\right)$ and valence band $\left(\Delta \mathrm{E}_{\mathrm{v}}\right)$ offsets at heterojunctions along with the material band gap control thermionic emission. A ratio of $\Delta \mathrm{Ec} / \Delta \mathrm{E}_{\mathrm{v}}=$ $0.7 / 0.3$ is usually considered for $\mathrm{InGaN} / \mathrm{GaN}$ and also for $\mathrm{AlGaN} / \mathrm{GaN}$ [17]. Three Si-doped $\mathrm{In}_{0.15} \mathrm{Ga}_{0.85} \mathrm{~N}$ well layers with the thickness of $35 \mathrm{~A}^{\circ}$, the refractive index $\mathrm{n}_{\mathrm{r}}=3$, the thermal conductivity $\mathrm{k}_{\mathrm{L}}=0.2 \mathrm{Wcm}^{-1} \mathrm{~K}^{-1}$ and the mobility $\mu=300 \mathrm{~cm}^{-2} \mathrm{~V}^{-1} \mathrm{~S}^{-1}$ are located in the centre of symmetric LD. Four Si-doped $\mathrm{In}_{0.02} \mathrm{Ga}_{0 .}{ }_{98} \mathrm{~N}$ barrier layers with the thickness of $70 \mathrm{~A}^{\circ}$, the refractive index $\mathrm{n}_{\mathrm{r}}=2.61$, the thermal conductivity $\mathrm{k}_{\mathrm{L}}=0.7 \mathrm{Wcm}^{-1} \mathrm{~K}^{-1}$ and the mobility $\mu=850 \mathrm{~cm}^{-2} \mathrm{~V}^{-1} \mathrm{~S}^{-1}$ surround quantum wells. A $200 \mathrm{~A}^{\circ}$ thick p-type $\mathrm{Al}_{0.2} \mathrm{Ga}_{0.8} \mathrm{~N}$ EBL with the refractive index $n_{r}=2.23$, the thermal conductivity $\mathrm{k}_{\mathrm{L}}=0.6 \mathrm{Wcm}^{-1} \mathrm{~K}^{-1}$ and the mobility $\mu=10 \mathrm{~cm}^{-2} \mathrm{~V}^{-1} \mathrm{~S}^{-1}$ used to stop electron leakage. A $0.1 \mu \mathrm{m}$-thick p-type GaN layer with the mobility of $\mu=10 \mathrm{~cm}^{-2} \mathrm{~V}^{-1} \mathrm{~S}^{-1}$, a $0.5 \mu \mathrm{m}$ thick ptype $\mathrm{Al}_{0.08} \mathrm{Ga}_{0.92} \mathrm{~N}$ layer with the mobility of $\mu=1.05 \mathrm{~cm}^{-2} \mathrm{~V}^{-1} \mathrm{~S}^{-1}$, and a $0.3 \mu \mathrm{m}$ thick p-type GaN layer with the mobility of $\mu=10 \mathrm{~cm}^{-2} \mathrm{~V}^{-1} \mathrm{~S}^{-}$ ${ }^{1}$ complete the laser structure. Other material parameters of these three layers are similar to ntype layers. The $0.1 \mu \mathrm{m}$ thick p-type and n-type $\mathrm{GaN}$ layers are the waveguide layers. The $0.5 \mu \mathrm{m}$ thick n-type and p-type $\mathrm{Al}_{0.08} \mathrm{Ga}_{0.92} \mathrm{~N}$ layers are the cladding layers to confine the carriers as well as the light released from the active region [15]. Inside the QWs, the physical model calculates the spontaneous recombination rate of self-consistently from the 
emission spectrum, outside the common recombination coefficients, where $\mathrm{B}=2 \times 10^{-11}$ $\mathrm{cm}^{3} \quad \mathrm{~s}^{-11}$ is applied. Defect-related recombination is known to be the main carrier loss mechanism in nitride devices. The Shockley-Read-Hall (SRH) recombination lifetime of electrons and holes is assumed to be $1 \mathrm{~ns}$. A very small Auger parameter of $\mathrm{C}=10^{-34}$ $\mathrm{cm}^{6} \mathrm{~s}^{-1}$ is estimated for GaN. Thermal resistance $\left(\mathrm{R}_{\mathrm{th}}\right)$ has a significant effect on the power roll-off, which is considered $75 \mathrm{~K} / \mathrm{W}$ in this study. In the asymmetric configuration, the p-type $\mathrm{Al}_{0.2} \mathrm{Ga}_{0.8} \mathrm{~N}$ electron blocking and $\mathrm{p}$-type $\mathrm{GaN}$ waveguide layers are removed, and the remaining part of the laser structure is kept the same as the conventional structure. The cavity length of the two LDs is $150 \mu \mathrm{m}$, and the ridge's width is $4 \mu \mathrm{m}$. The reflectivity of both mirrors is set as 0.5 . The structures of the symmetric and asymmetric multi-quantum well (MQW) lasers are represented in Figs. 1(a) and (b), respectively.

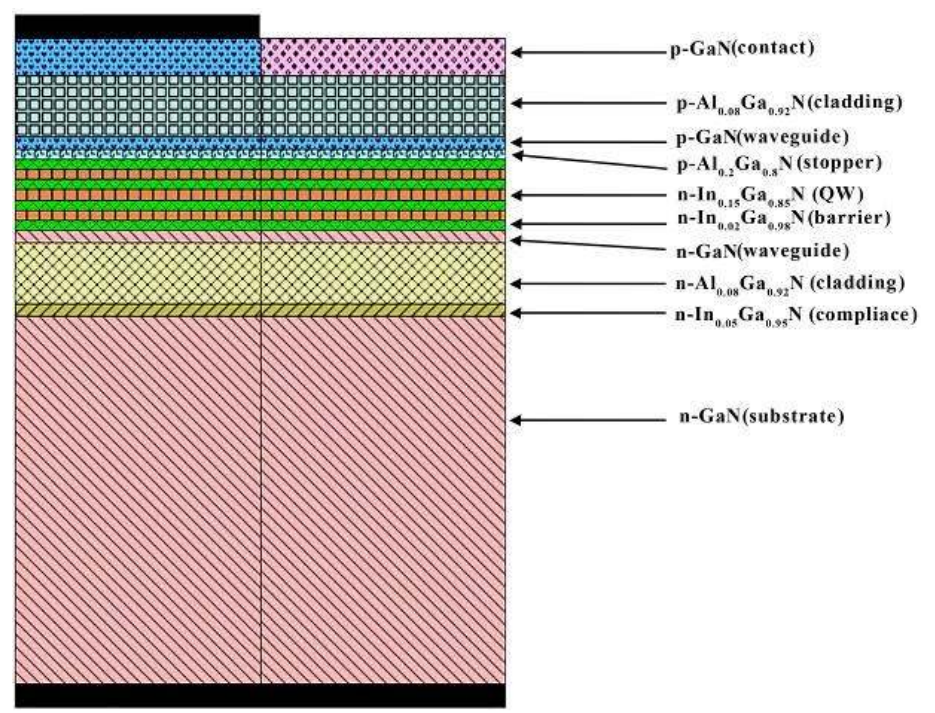

(a)

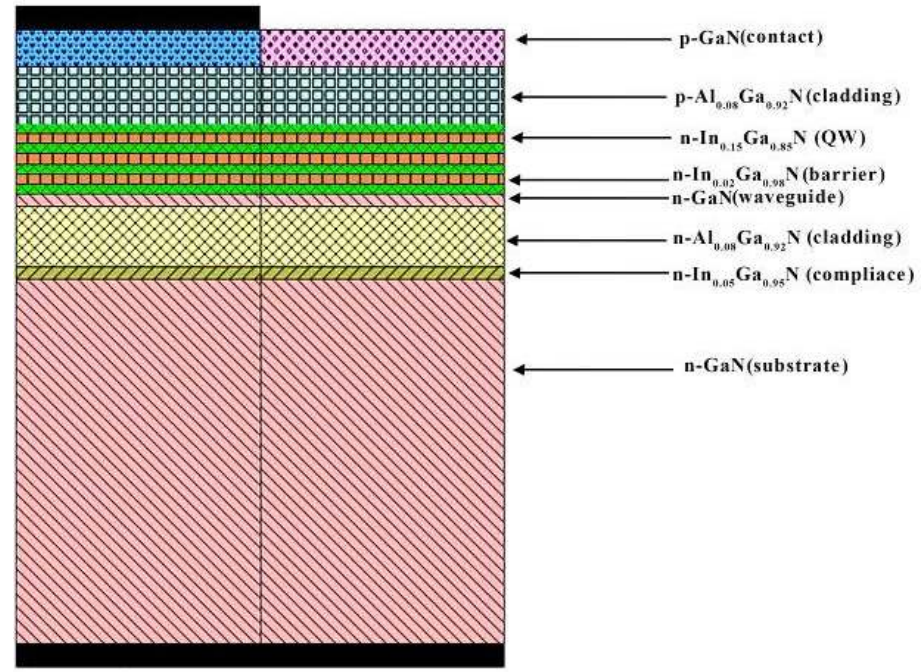

(b)

Fig. 1. The (a) symmetric and (b) asymmetric InGaN MQW LD structures.

Threshold current, maximum output power, and lasing wavelength of a150 $\mu \mathrm{m}$ cavity length LD are $50 \mathrm{~mA}, 5.5 \mathrm{~V}$ and $400.2 \mathrm{~nm}$, respectively at the stage temperature of $20^{\circ} \mathrm{C}$ [15].

\section{IV.SIMULATION RESULTS AND DISCUSSION}

Figure 2 compares the simulated (dashed line) and experimental (solid line) L-I and V-I 
characteristics for the continuous-wave operation at the $20^{\circ} \mathrm{C}$ stage temperature. Considering the good agreement with the experiment results, one can make use of simulation results for quantitative analysis of the laser diode performance. For many applications, it is highly essential to obtain high output power as well as high efficiency. To this end, the laser structure is required to be optimized, which can be done by profoundly comprehending physical phenomena influencing the laser performance at high power operation.

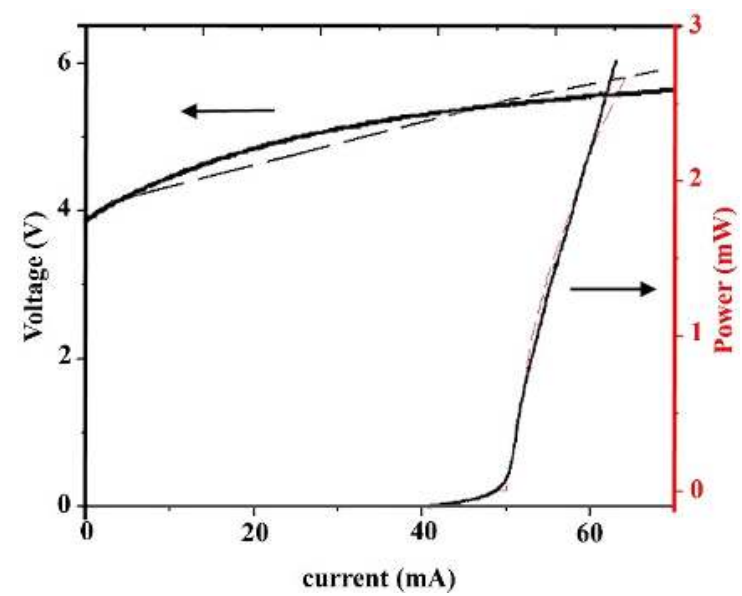

Fig. 2. The simulated (dashed) and experimental (solid) L-I and I- V features for the continuous wave operation at the $20^{\circ} \mathrm{C}$ stage temperature.

In GaN-based systems, an AlGaN alloy with a wider bandgap forms cladding layers for creating optical confinement. However, as lattice constants in the $\mathrm{AlGaN}$ compound are significantly smaller, the design of the GaN laser diode cladding is strongly limited in terms of tensile strain in $\mathrm{AlGaN}$ layers deposited on the GaN substrate. Since the new quadruple asymmetric waveguide structure makes use of the $\mathrm{AlGaN}$ p-cladding layer to confine electrons in the active region, the new LD performance is influenced by the properties of this layer [18]. Choosing the percent of Al composition for using in the AlGaN p-cladding layer is very important. In order to optimize the performance of the proposed laser structure, the asymmetric cladding structure is studied by varying the $\mathrm{Al}$ composition (x-factor) of the $\mathrm{Al}_{\mathrm{x}} \mathrm{Ga}_{1-\mathrm{x}} \mathrm{N}$ pcladding layer. For better optical field and carrier confinement, a low Al composition
$\mathrm{Al}_{\mathrm{x}} \mathrm{Ga} 1_{-\mathrm{x}} \mathrm{N}$ cladding layer is used in the actual GaN-based laser diode. High Al composition increases a barrier for holes, reducing the injection of the hole into the active region. Besides, growth conditions of such layers are different from InGaN quantum wells, so using high Al composition may cause to degradation of QWs. At the first step, this paper aims to determine optimum Al composition, where $\Gamma_{\mathrm{MQW}}$ is maximized. Low optical confinement initiates a damaged cycle in the active region, resulting in a low modal gain. The low modal gain requires a higher carrier density in the quantum well to reach the threshold lasing. With the increased quantum well carrier density, the well can be expected to have a higher quantity of non-radiative and spontaneous recombination. Consequently, the use of higher injection current is required to reach the threshold condition. This leads to a lowered output power, which, in turn, causes the optical output power to shift toward a higher voltage. The amount of dissipated heat grows in the case the output power is low. So, the temperature increases in the active layer, and the material gain significantly reduces. Moreover, a higher junction temperature results in a significant index drop, that causes to decrease confinement and may also lead to a further reduced modal gain. Thus, for the highest efficiencies at high operating temperature and power, it is vital to stop this cycle in the quantum well using a high confinement factor [19]. Here, the composition of $\mathrm{Al}$ in the $\mathrm{Al}_{\mathrm{x}} \mathrm{Ga}_{1-\mathrm{x}} \mathrm{N}$ n-cladding layer is fixed at $8 \%$; furthermore, considering experimental reports, the aluminium composition in the $\mathrm{Al}_{\mathrm{x}} \mathrm{Ga}_{1-\mathrm{x}} \mathrm{N}$ p-cladding layer varies from $2 \%$ to $10 \%$ [18]. Figure 3 indicates $\Gamma_{\mathrm{MQW}}$ and $\Gamma$ variations as the function of $\mathrm{Al}$ composition in the AlGaN p-cladding layer. The confinement factor of the QWs non-uniformly becomes weak by increasing the $\mathrm{Al}$ composition from $2 \%$ to $10 \%$. In the new asymmetric waveguide, the $\mathrm{Al}_{\mathrm{x}} \mathrm{Ga}_{1-\mathrm{x}} \mathrm{N}$ p-cladding layer is used for optical filed confinement, which has a smaller refractive index than the $\mathrm{GaN}$ n-waveguide layer. Thus, the optical field is expected to be more expanded in the n-side of the waveguide. When the refractive index of the $\mathrm{Al}_{\mathrm{x}} \mathrm{Ga}_{1-\mathrm{x}} \mathrm{N}$ pcladding layer is increased by decreasing the $\mathrm{Al}$ 
composition, the refractive index contrast between the InGaN barrier and $\mathrm{AlGaN}$ pcladding layers also increases, which causes an increase in $\Gamma_{\mathrm{MQW}}$. In order to choose the optimum value of the Al composition, Fig. 3 must be carefully studied. The MQW confinement factor variation is somehow complicated. As observed in Fig. 3, for LDs with $\mathrm{Al}$ compositions of $5 \%, 7 \%$, and $10 \%$ in the $\mathrm{Al}_{\mathrm{x}} \mathrm{Ga}_{1-\mathrm{x}} \mathrm{N}$ p-cladding layer, the $\mathrm{QW}$ optical confinement factor reduction is well observed. For LDs with Al compositions less than 4\%, $\Gamma_{\mathrm{MQW}}$ does not change significantly.

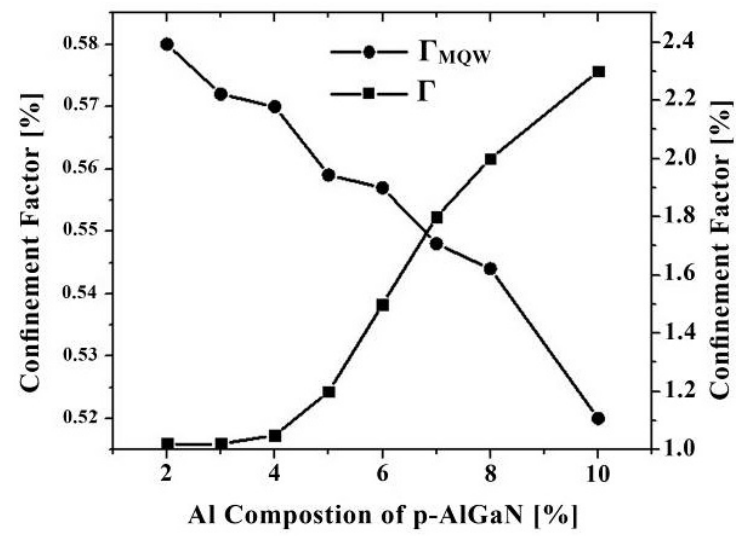

Fig. 3. $\Gamma_{\mathrm{MQW}}$ and $\Gamma$ as an $\mathrm{Al}$ composition function in the $\mathrm{Al}_{\mathrm{x}} \mathrm{Ga}_{1-\mathrm{x}} \mathrm{N}$ p-cladding layer.

In this diagram, the $\Gamma$ is also shown by square line. The optical intensity in the active region is confined with the confinement factor $\Gamma_{\mathrm{MQw}}$; while the other part of it spreads outside of the MQW region into the waveguide and cladding layers of the new structure with the confinement factor $\Gamma$. Relatively complicated relation is observed between $\Gamma$ and $\mathrm{x}$. It is seen that the $\Gamma-x$ can be approximately divided into two parts according to its slope. $\Gamma$ is roughly constant when $\mathrm{x} \leq 0.4$. When $0.4 \leq \mathrm{x} \leq 0.10$ the optical confinement factor $\Gamma$ increases with increasing $\mathrm{x}$. It is clear from the plot that when the $\mathrm{x}$ changes from $2 \%$ to $10 \%$, the $\Gamma$ increases about $17 \%$. This means by enhancing the $\mathrm{Al}$ mole fraction, the free carrier absorption also increases about $17 \%$. Thus the $\mathrm{AlGaN} p$ cladding layer with the $4 \% \mathrm{Al}$ composition is considered as the optimum construction, which simultaneously produces a high optical confinement factor, a low tensile strain, and low free carrier absorption.
To confirm that the $\mathrm{Al}_{\mathrm{x}} \mathrm{Ga}_{1-\mathrm{x}} \mathrm{N}$ p-cladding with $4 \%$ mole fraction is the optimum layer, the threshold current, output power, and slope efficiency of LDs containing various $\mathrm{Al}$ compositions in $\mathrm{Al}_{\mathrm{x}} \mathrm{Ga}_{1-\mathrm{x}} \mathrm{N}$ p-cladding layers are compared in Fig. 4 As expected, by decreasing the composition of $\mathrm{Al}$ in the $\mathrm{Al}_{\mathrm{x}} \mathrm{Ga}_{1}$ ${ }_{x} \mathrm{~N}$ p-cladding layer, the threshold current decreases and the slope efficiency and the output power increase. The threshold current, slope efficiency, and output power of LDs with $2 \%$ and $4 \% \mathrm{Al}$ compositions do not change significantly. The reduction of the threshold current occurs because of the increased $\Gamma_{\mathrm{MQW}}$. As it is known, the LD slope efficiency is affected by optical losses consisting of cladding and waveguide losses.

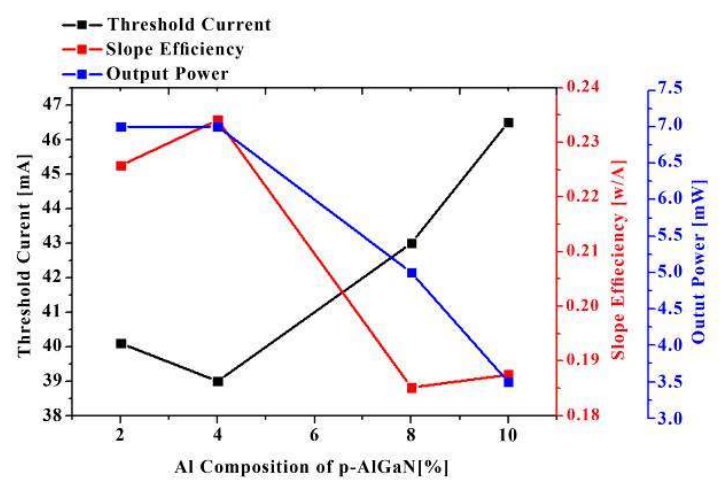

Fig. 4. Threshold current, output power and slope efficiency of LDswith various compositions of $\mathrm{Al}$ in the $\mathrm{Al}_{\mathrm{x}} \mathrm{Ga}_{1-\mathrm{x}} \mathrm{N}$ p-cladding layer.

The optical field overlap with the high-doped layers determines the mentioned optical losses. The optical field distributions of LDs with different $\mathrm{Al}$ compositions are presented in Fig. 5 By considering this Figure, one can notice that the maximum optical field is localized in the MQWs of LDs due to the refractive index engineering. The optical field overlapping with highly n-doped waveguide layer and cladding layer decreases with decreasing $\mathrm{Al}$ composition. It does not change significantly in the p-side of LDs and MQWs. So, the optical losses reduce in n- side of LDs and the slope efficiency enhances. As discussed earlier, the free carrier absorption decreases with increasing $\mathrm{x}$, which is another reasons for improving the new laser diode performance at low Al mol fraction. The characterizations of 
LDs with $2 \%$ and $4 \% \mathrm{Al}$ compositions do not change significantly, as it can be observed.

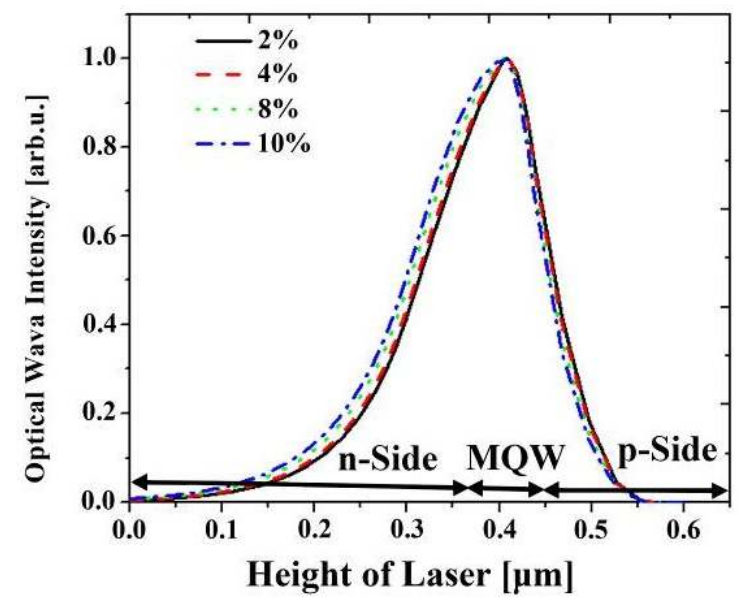

Fig. 5. Optical field distributions for LDs with various compositions of $\mathrm{Al}$ in the $\mathrm{Al}_{\mathrm{x}} \mathrm{Ga}_{1-\mathrm{x}} \mathrm{N}$ pcladding layer.

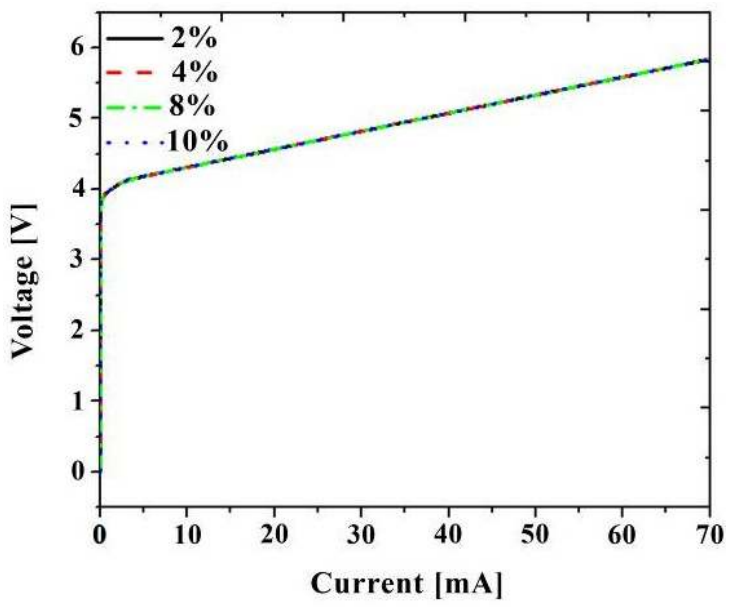

Fig. 6. V-I curves for LDs with different compositions of $\mathrm{Al}$ in the $\mathrm{Al}_{\mathrm{x}} \mathrm{Ga}_{1-\mathrm{x}} \mathrm{N}$ p-cladding layer.

Figure 6 represents the voltage-current characteristics of the devices. All LDs possess the same voltage characteristics owing to having a similar waveguide design (bandgap, doping, and thickness) to that of all the proposed devices. It means that the $\mathrm{Al}$ composition does not affect LDs series resistances.

A critical laser parameter is a p-cladding thickness, which is vital for high power laser performance. The lasing mode functions as an evanescent wave in LDs with an intensity exponentially decaying into cladding layers. In case the cladding layer thickness is much more extensive compared to a penetration depth in the decaying mode, optical losses related to laser emission penetration into passive waveguides are negligible.

By decreasing the composition of $\mathrm{Al}$ in the $\mathrm{Al}_{\mathrm{x}} \mathrm{Ga}_{1-\mathrm{x}} \mathrm{N}$ p-cladding layer, the optical field spreads into the LD centre. To optimize the laser performance, the p-cladding layer thickness must be adjusted. Recently, a narrow asymmetric waveguide structure was used as a suitable construction for high power laser diode operation. In many theoretical and experimental studies about the GaN-based laser, the p-cladding layer thickness is less than the n-cladding layer thickness. Reasons for the use of relatively thin claddings include preventing an increment in the diode series resistance, avoiding the creation of cracks, and other defects and also reducing growth time. Thus, the p-cladding layer's thickness decreases, and the results are compared in the rest of this article. By considering the experimental results, the p-cladding thickness reduces form $0.5 \mu \mathrm{m}$ to $0.1 \mu \mathrm{m}$. Figure 7 represents the $\Gamma_{\mathrm{MQW}}$ and $\Gamma$ as the p-AlGaN thickness function. The optical confinement factor $\left(\Gamma_{\mathrm{MQW}}\right)$ refers to the ratio of light intensity inside the MQW to the sum of light intensity outside and inside the MQW. By decreasing the p-cladding layer thickness, the total thickness of LD also decreases. Thus, the enhancement of the optical confinement factor is expected, as confirmed in Fig. $7 \mathrm{LD}$ with the $0.1 \mu \mathrm{m}$ p-cladding thickness produces the highest $\Gamma_{\mathrm{MQW}}$.

The effect of $\mathrm{p}-\mathrm{AlGaN}$ cladding layer thickness on the $\Gamma$ is also investigated. As can be seen, $0.1 \mu \mathrm{m}$ has the lowest $\Gamma$, so it has the lowest free carrier absorption. For other thicknesses, the $\Gamma$ enhancement does not change significantly. This means that the free carrier absorption is saturated for higher thicknesses. To ensure that $0.1 \mu \mathrm{m}$ can be considered as the optimal thickness, the characterizations of LDs are investigated. Figure 8 indicates the threshold current, output power, and slope efficiency of LDs with different AlGAN p-cladding layer thicknesses. As observed, the threshold current 
decreases by decreasing the p-cladding thickness, because of increasing the optical confinement factor. Furthermore, low optical losses can be ascribed to the small overlap between the optical field and the p-cladding, where the effect of free carrier density is higher compared to the n-side of LD. Therefore, the output power and the slope efficiency increase. As expected, due to free carrier absorption saturation, the output power, and the slope efficiency do not change significantly when the thickness is more than $0.1 \mu \mathrm{m}$.

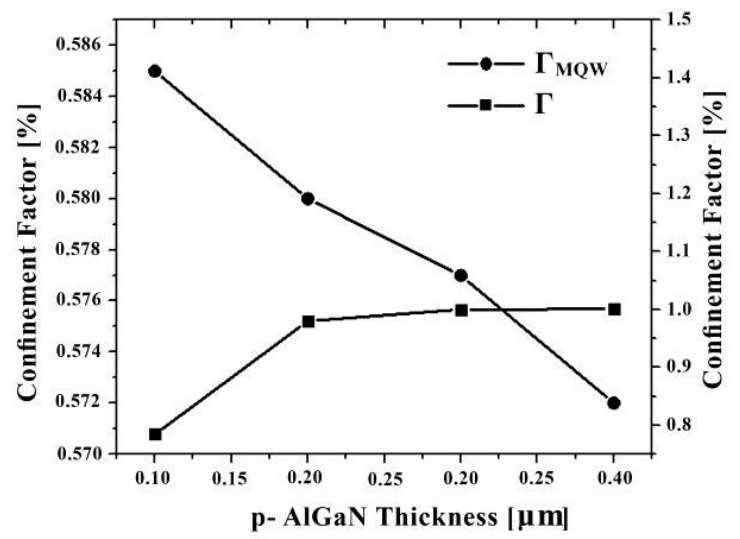

Fig. 7. $\Gamma_{\mathrm{MQW}}$ and $\Gamma$ as the p-AlGaN thickness.

Namely, since the p-doped AlGaN layer has resistivity higher than the n-doped AlGaN layer, reducing the resistance of the p-doped cladding layer by decreasing its thickness is a promising method to improve the LD characterization without increasing voltage and optical propagation losses.

V-I curves for LDs with different p-AlGaN thicknesses are shown in Fig. 9. As expected, the operating voltage decreases by decreasing the p-cladding thickness.

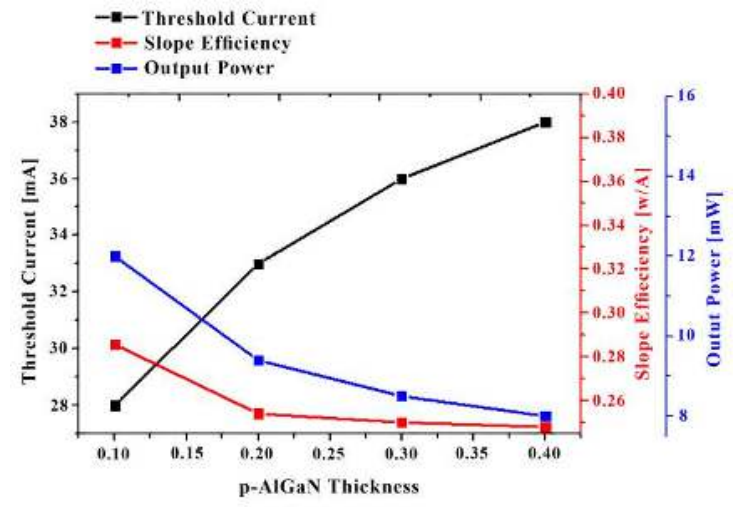

Fig. 8. Threshold current, output power and slope efficiency of LDs with different p-AlGaN thicknesses.

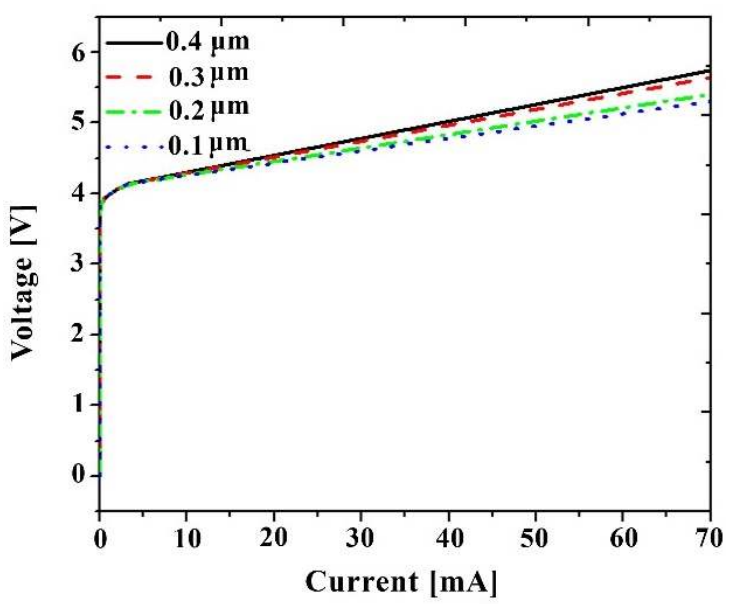

Fig. 9. V-I curves for LDs with different p-AlGaN thicknesses.

The optimization of p-cladding doping levels is very crucial in designing of GaN-based laser structures since the laser power is limited due to a high optical loss in the AlGaN p-cladding layer. Most of the studies have discovered that the parameters of diodes are strongly affected by the p-cladding doping level. Threshold current, slope efficiency, output power and operating voltage for LDs with different $\mathrm{p}$ AlGaN doping levels are respectively shown in Figs. 10 and 11. Due to the well optical field confinement in the LD center and its small overlap with the p-doped layer, the laser output power, and the slope efficiency do not change significantly by increasing the p-doping level in the AlGaN cladding layer.

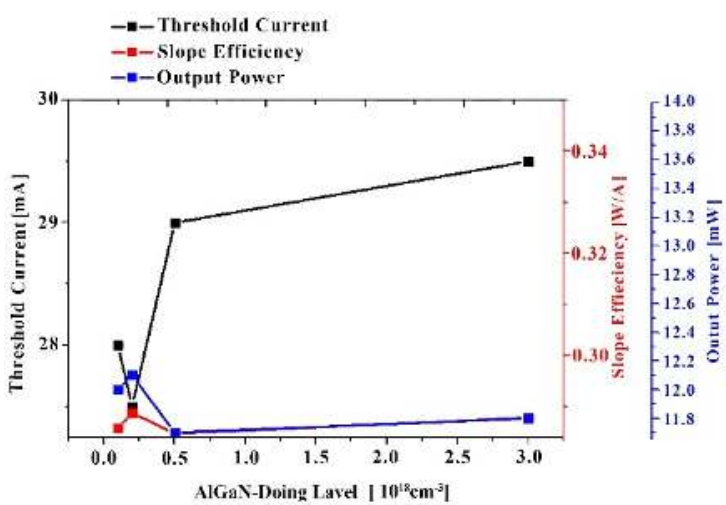

Fig. 10. Threshold current, output power and slope efficiency of LDs with different p-AlGaN doping levels. 
The reduction in the thickness of the AlGaN pcladding layer leads to a decrease in the layer doping level effect on determining the LD series resistance Therefore, the V-I curves of LDs with different p-doping levels of the AlGaN cladding layer do not differ much from each other.

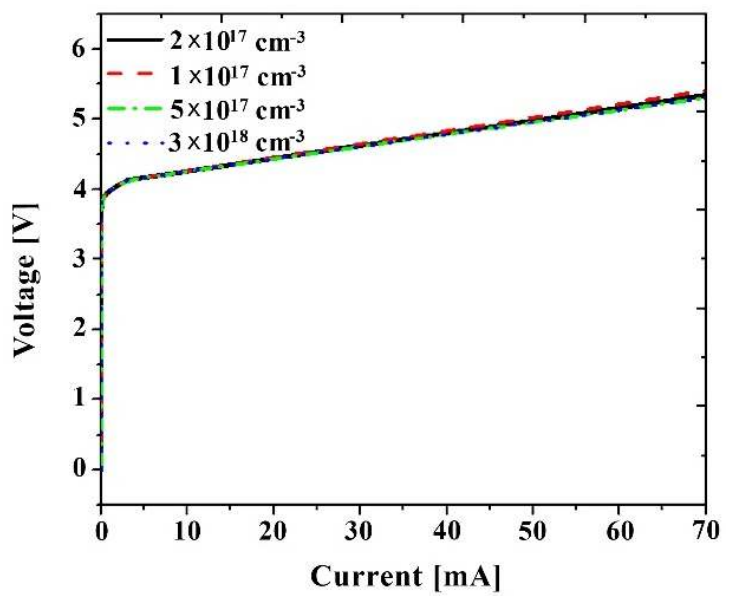

Fig. 11. V-I curves for LDs with different p-AlGaN doping levels.

It is the unique characterization of the new quadruple asymmetric waveguide structure. By carefully investigating these plots, it can be noticed that LD with $2 \times 10^{17} \mathrm{~cm}^{-3}$ doping level shows better performance, and thus, it is considered as the optimized doping level.

L-I and I-V curves of the conventional and new structures are presented in Figs. 12 and 13, respectively. These plots show that the new quadruple asymmetric LD enhances the output power and slope efficiency from $3 \mathrm{~mW}$ and $0.022 \mathrm{~W} / \mathrm{A}$ to $12.1 \mathrm{~mW}, \quad 0.29 \mathrm{~W} / \mathrm{A}$, respectively.

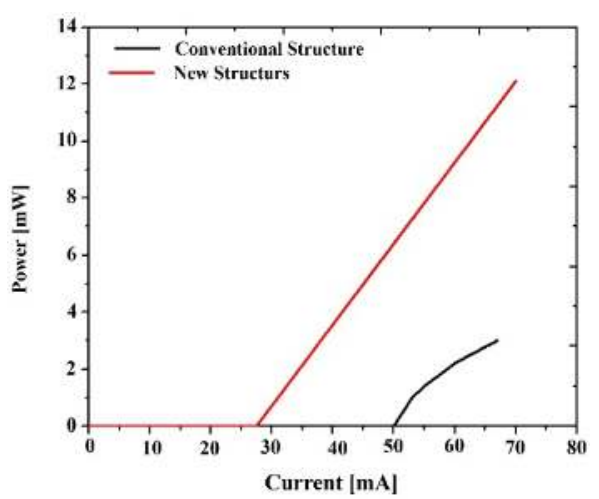

Fig. 12. L-I curves for the conventional and the optimized new structure LDs

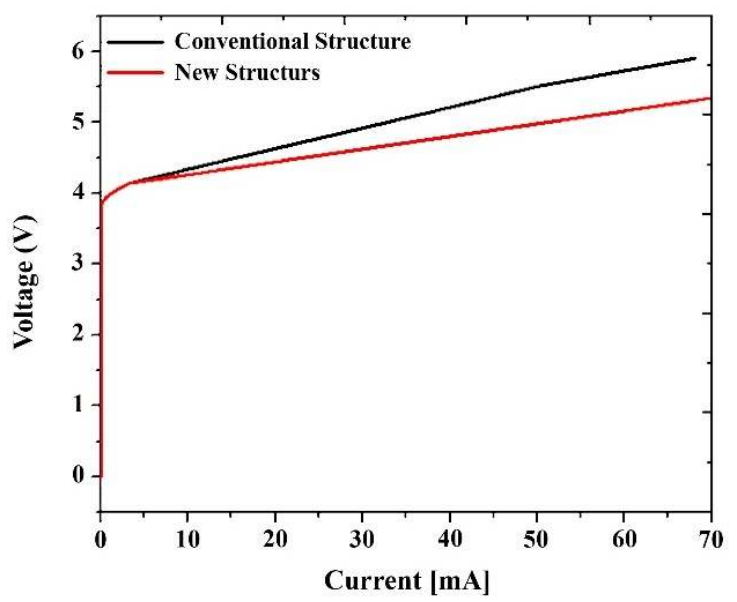

Fig. 13. V-I curves for the conventional and the optimized new structure LDs

It also reduces the threshold current from 50 $\mathrm{mA}$ to $27.5 \mathrm{~mA}$. The reduction of the operating voltage of the new quadruple asymmetric can be seen in the Fig. 13 Highly p-doped EBL elimination is the main reason for this reduction.

Other reasons for the better operation of the optimized new quadruple asymmetric laser structure are discussed in the subsequent of this investigation. Figure 14 compares the hole densities of the conventional and the new structure LDs.

The optimized new quadruple asymmetric LD enhances the hole density. The radiative recombination rates of the conventional and the new structures are displayed in Fig. 15. The rate

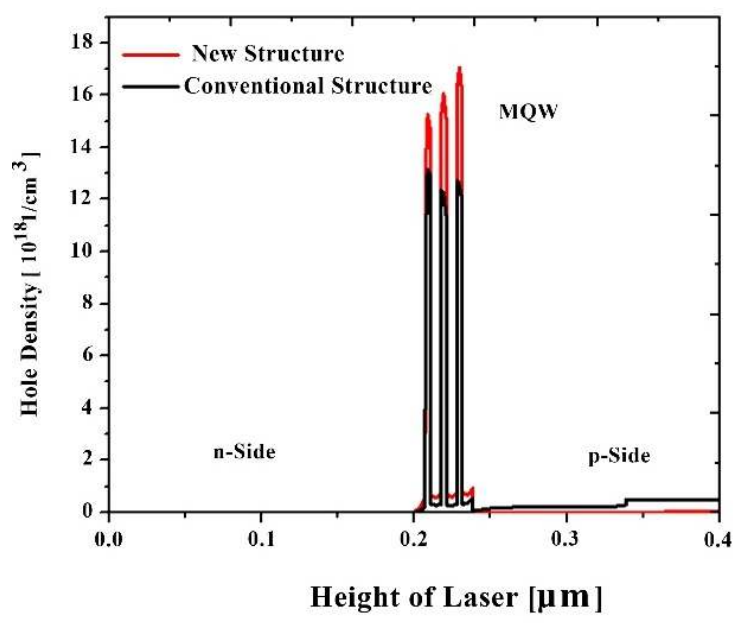

Fig. 14. Hole densities of the conventional and the optimized new quadruple asymmetric waveguide LDs. 
quadruple asymmetric structure is much larger than that of the conventional LD; because the hole injection is significantly improved in the new structure, and more holes are accumulated within the MQW active region so that they contribute in the recombination process.

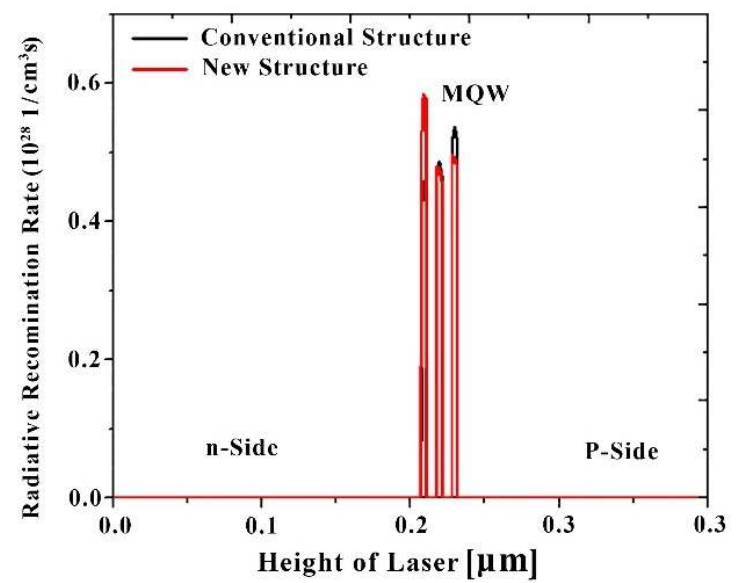

Fig. 15. Radiative recombination rates of the conventional and the optimized new quadruple asymmetric waveguide LDs.

\section{Conclusion}

It should be mentioned that, in this study, for the first time, a quadruple asymmetric waveguide was introduced and applied to the blue GaN-based laser structure. To this end, the experimental GaN-based laser was considered and modified. In the new proposed waveguide structure, at the first step, p-waveguide and electron blocking layers were omitted and then a triple asymmetry was considered in the design of the AlGaN p-cladding layer inside the waveguide structure. The performances of the conventional and proposed laser structures were theoretically studied using the simulation software PICS3D. 3D simulations of carrier transport, optical wave-guiding, and selfheating were combined self-consistently in the software. This study demonstrated that GaNbased blue LDs with the adequately selected $\mathrm{Al}$ composition, thickness, and doping level for the p-cladding layer in the newly proposed quadruple asymmetric waveguide exhibited high output power and slope efficiency. Under a proper new quadruple asymmetric waveguide structure modification, the optimized value of Al composition, thickness, and doping level in $\mathrm{p}-\mathrm{AlGaN}$ was calculated $4 \%, 0.1 \mu \mathrm{m}$, and
$2 \times 10^{17} \mathrm{~cm}^{-3}$, respectively. The simulation results showed that the new quadruple asymmetric laser diode enhanced the output power and slope efficiency from $3 \mathrm{~mW}$ and $0.022 \mathrm{~W} / \mathrm{A}$ to $12.1 \mathrm{~mW}, 0.29 \mathrm{~W} / \mathrm{A}$, respectively. It also reduced the threshold current from 50 $\mathrm{mA}$ to $27.5 \mathrm{~mA}$.

\section{ACKNOWLEDGMENT}

I express my sincere appreciation to the managers of Cross Light Inc. for providing me with the advanced three-dimensional PICS3D simulation program (version 2008.12) and their kind support.

\section{REFERENCES}

[1] H.Y. Ryu, K.H. Ha, J.K. Son, H.S. Paek, Y.J. Sung, K.S. Kim, and O.H. Nam, "Comparison of Output Power of InGaN Laser Diodes for Different Al Compositions in The AlGaN nCladding Layer," J. Appl. Phys. Vol. 105, pp. 103102 (1-4), 2009.

[2] B.S. Ryvkin, E.A. Avrutin, and J.T. Kostamovaara, "Narrow Versus Broad Asymmetric Waveguides for Single-Mode High-Power Laser Diodes," J. Appl. Phys. Vol. 114, pp. 013104 (1-4), 2013.

[3] J. M.T. Huikari, E.A. Avrutin, B.S. Ryvkin, J.J. Nissinen, and J.T. Kostamovaara, "HighEnergy Picosecond Pulse Generation by Gain Switching in Asymmetric Waveguide Structure Multiple Quantum Well Lasers," IEEE. J. Sel. Top. Quant. Vol. 21, pp. 1501206 (1-6), 2015.

[4] B.S. Ryvkin, E.A Avrutin, and J.T. Kostamovaara, "Optical Loss Suppression in Long-Wavelength Semiconductor Lasers at Elevated Temperatures by High Doping of The n-Waveguide," Semicond. Sci. Technol. Vol. 33, pp. 105010 (1-8), 2018.

[5] X. Li, D. Zhao, D. Jiang, D. Jiang, P. Chen, Z. Liu, J. Zhu, M. Shi, D. Zhao, and W. Liu, "Suppression of Electron Leakage in $808 \mathrm{~nm}$ Laser Diodes with Asymmetric Waveguide Layer," J. Semicond. Vol. 37, pp. 014007 (1-4), 2016.

[6] F.I. Zubov, M.V. Maximov, M. Shernyakov, M. Yu, N.V. Kryzhanovskaya, E.S. Semenova, K. Yvind, L.V. Asryan, and A.E. Zhukov, "Suppression of Sublinearity of Light-Current Curve in $850 \mathrm{~nm}$ Quantum Well Laser with 
Asymmetric Barrier Layers," Electron. Lett. Vol. 51 pp. 1106-1108, 2015.

[7] S.P. Abbasi and M.H. Mahdieh, "Active Layer Position Optimization in Asymmetric AlGaInAs/AlGaAs Semiconductor Laser Diode Structures," Opt. Commun. Vol. 402, pp. 624-629, 2017.

[8] G.Z. Racz, N. Bamiedakis, and R. Penty, "Mode-Selective Optical Sensing Using Asymmetric Waveguide Junctions," Sens. Actuators A. Phys. Vol. 233, pp. 91-97, 2015.

[9] S. Nakamura, S. Pearton, and G. Fasol, The Blue Laser Diode, Springer, Germany, 2000.

[10] Gh. Alahyarizadeh, Z. Hassan, S.M. Thahab, F. K. Yam, and A.J. Ghazai, Performance characteristics of deep violet InGaN DQW laser diodes with $\mathrm{InGaN} / \mathrm{GaN}$ superlattice waveguide layers," Optik, Int. J. Light Electron Opt. Vol. 125, pp. 341-344, 2014.

[11] Gh. Alahyarizadeh, Z. Hassan, S.M. Thahab, F.K. Yam, and A.J. Ghazai, "Numerical study of performance characteristics of deep violet InGaN DQW laser diodes with AlInGaN quaternary multi quantum barrier electron blocking layer," Optik, Int. J. Light Electron Opt. Vol. 124, pp. 6765-6768, 2013.

[12] Gh. Alahyarizadeh, M. Amirhoseiny, and Z. Hassan, "Effect of different EBL structures on deep violet InGaN laser diodes performance," Opt. Laser Technol. Vol. 76, pp. 106-112, 2016.

[13]Gh. Alahyarizadeh and R. Rahmani, "Enhancement of performance characteristics of violet InGaN DQW laser diodes using InGaNGaN multilayer barriers," Optik, Int. J. Light Electron Opt.127, pp. 7635-7641, 2016.

[14]Gh. Alahyarizadeh, Z. Hassan, S.M. Thahab, and F.K. Yam, "Improvement of the performance characteristics of deep violet InGaN multi-quantum-well laser diodes using step-graded electron blocking layers and a delta barrier," J. Appl. Phys. Vol. 113, pp. 123108 (1-8), 2013.

[15] S. Nakamura, "InGaN-Based Blue Laser Diodes," IEEE. J. Sel. Top Quant. Vol. 3, pp. 712-718, 1997.

[16] Available online on www.crosslight.com.

[17] J. Piprek, Nitride Semiconductor Devices: Principles and Simulation, Weinheim: WileyVCH, 2007.

[18] D.P. Bour, M. Kneissl, G. Van de Walle, A.G. Evans, L.T. Romano, M. Teepe, R. Wood, T. Schmidt, S. Schoffberger, and N.M. Johnson "Design and Performance of Asymmetric Waveguide Nitride Laser Diodes," IEEE J. Quantum Electron. Vol. 36, pp. 184-191, 2000.

[19] T. Kaul, G. Erbert, A. Maaßdorf, S. Knigge, and P. Crump, "Suppressed Power Saturation Due to Optimized Optical Confinement in 9xx nm High-Power Diode Lasers That Use Extreme Double Asymmetric Vertical Designs," Semicond. Sci. Technol. Vol. 33 pp. 035005 (1-9), 2018.

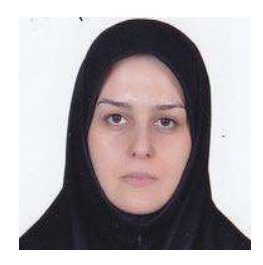

Zahra Danesh Kaftrouddi is an Associate Professor of Physics in the Department of Engineering Sciences of University of Guilan. She received her B.Sc. degree from the Iran University of Science and Technology in 1998 and M.Sc. and Ph.D. degrees from University of Guilan in 2003 and 2010, respectively. She has academic skills in optoelectronic device simulation. 


\section{THIS PAGE IS INTENTIONALLY LEFT BLANK.}

